\title{
PENELITIAN UJI KUAT TEKAN BETON DENGAN MEMANFAATKAN AIR LIMBAH TETES TEBU DAN ZAT ADDITIVE CONCRETE
}

\author{
Mochamad Ahsin Anshori *1, Ahmad Ridwan ${ }^{2}$, Yosef Cahyo SP 3. \\ ${ }^{1,2,3}$ Fakultas Teknik, Universitas Kadiri. \\ e-mail:*1 $\frac{\text { ahsinanshori@gmail.com, }}{{ }^{2} \text { yosmad_ridwan@unik-kediri.ac.id }}$,
}

\begin{abstract}
Concrete has a weakness that is having a low tensile strength and brittle so that the concrete is given steel reinforcement to anticipate it. This addition was carried out to study and determine the effect of sugarcane waste on compressive strength, flexural strength on normal quality concrete with the addition of $0 \%, 10 \%$, $20 \%$ and $30 \%$ in compressive loads. Testing is done after 28 days. Concrete with the addition of $30 \%$ sugar cane is more capable of producing high flexural strength than the others. Addition of sugar cane drops resulted in optimum compressive strength of $10 \%, 16.75 \mathrm{MPa}, 20 \%, 16.55 \mathrm{MPa}, 30 \%, 16.40 \mathrm{MPa}$. For the highest flexural strength of concrete in the 15/15/60 beam sample, the concrete mixture was added to 30\% sugar cane by $5.00 \mathrm{MPa}$, higher than normal concrete $4.96 \mathrm{MPa}$.
\end{abstract}

Keywords: $\quad$ Sugar Cane Waste, Compressive Strength, Concrete Flexural Strength, Concrete

\begin{abstract}
Abstrak
Beton mempunyai kelemahan yaitu mempunyai kuat tarik yang rendah dan bersifat getas (brittle) sehingga beton diberi tulangan baja untuk mengantisipasinya. Penambahan ini dilakukan untuk mempelajari dan mengetahui pengaruh limbah tetes tebu terhadap kuat tekan, kuat lentur pada beton mutu normal dengan penambahan 0\%, 10\%, 20\% dan 30\% pada beban tekan. Pengujian dilakukan setelah 28 hari. Beton dengan penambahan tetes tebu $30 \%$ lebih mampu menghasilkan nilai kuat lentur tinggi dari pada yang lainya. Penambahan limbah tetes tebu menghasilakan kuat tekan optimum yaitu, $10 \%, 16,75 \mathrm{MPa}, 20 \%, 16,55 \mathrm{MPa}$, $30 \%, 16,40 \mathrm{MPa}$. Untuk kuat lentur beton pada sampel balok 15/15/60 yang paling tinggi yaitu pada campuran beton penambahan tetes tebu $30 \%$ sebesar 5,00 MPa, lebih tinggi dari pada beton normal 4,96 MPa.
\end{abstract}

Kata Kunci : $\quad$ Limbah Tetes Tebu, Kuat Tekan, Kuat Lentur Beton, Beton 


\section{PENDAHULUAN}

Beton merupakan campuran yang berisi pasir, krikil/ batu pecah serta semen dan air yang sering di gunakan dalam berbagai macam bangunan konstruksi, beton berperan penting dalam pembangunan gedung maupun jembatan, [1][2]. Beton sendiri memiliki berbagai kelebihan, salah satunya adalah beton mampu memikul beban tekan yang berat dibanding dengan bahan lainnya, [3][4].

Berdasarkan kuat tekannya, mutu beton dibagi menjadi 3 jenis, yaitu beton mutu rendah (low strength concrete), beton mutu sedang (medium strength concrete) dan beton mutu tinggi (high strength concrete) dimana beton merupakan pilihan yang paling tepat untuk membuat bangunan bertingkat tinggi [5][6].

Penelitian yang di lakukan adalah dengan melakukan pecobaan pembuatan beton dengan memanfaatkan limbah air tetes tebu sebagai campuran air pada umumnya [7]. Pemanfaatan limbah itu sendiri bertujuan untuk mengetahui kualitas beton yang hal ini beton apakah memenuhi ketentuan syarat yang di berikan SNI, [8].

Menurut Setiawan (2003) banyak bangunan infrastruktur yang dibangun lebih dari 30 tahun yang lalu masih tetap berdiri, [9] namun seiring bertambahnya usia dan perubahan pembebanan pada bangunan tersebut tingkat kelayakan menjadi berkurang, [6][10]. Pada jembatan jalan raya misal, perubahan beban volume kendaraan dalam kurun waktu tertentu akan memperlemah struktur tersebut bahkan bisa berakhir dengan keruntuhan, [11][12]. Fenomena seperti ini disebut fatik atau kegagalan dibawah beban berulang

Berbagai penelitian telah dilakukan untuk mengatasi kelemahan beton ini. Dalam penelitian Soroushian \& Bayasi (1987), kuat tarik pada beton dapat ditingkatkan dengan cara penambahan serat-serat pada adukan beton agar retak-retak yang mungkin terjadi akibat tegangan tarik pada daerah beton tarik dapat ditahan oleh serat-serat tambahan ini, sehingga kuat tarik beton serat dapat lebih tinggi dibanding kuat tarik beton biasa [13].

\section{METODE PENELITIAN}

\subsection{Lokasi Penelitian.}

Penelitian ini dilakukan di Laboratorium Teknik Sipil Universitas Kadiri, pada awal bulan maret dan selesai pada bulan juni dengan menggunakan metode Eksperimen.

\subsection{Kepustakaan}

Dalam SNI 2847:2013, [14]. Beton adalah campuran semen Portland, agregat halus, agregat kasar, dan air, dengan atau tanpa bahan campuran tambahan (admixture). 
Beton normal yang mempunyai berat isi $2200-2500 \mathrm{~kg} / \mathrm{m}^{3}$ menggunakan agregat alam yang dipecah atau tnapa dipecah yang tidak menggunakan bahan tambahan, [15].

Jenis penelitian yang dilakukan yaitupenelitian experimental. Penelitian pertama menguji kadr lumpur pada agregat halus. Setelah mendapat yang sesuai dengan peraturan pembuatan beton dengan kadar lumpur maksimal 5\%., dilanjutkan dengan benda uji 15/15/15cm dan balok 15/15/60cm. Benda uji berbentuk kubus 10 buah dengan penambahan tetes tebu 0\%, 10\%, 20\%, $30 \%$ dan pada benda uji balok 4 buah masing-masing penambahan tettes tebu $0 \%, 10 \%, 20 \%$, $30 \%$. Pengujian dilakukan pada saat beton berusia 28 hari.

\section{HASIL DAN PEMBAHASAN}

\subsection{Pengujian Kadar lumpur pada agregat halus}

Setelah diaduk dan di diamkan 24 jam sampai dengan kondisi air berubah menjadi tidak keruh kita dapat mengetahui berapa persen kandungan kadar lumpur tersebut yaitu, [16] :

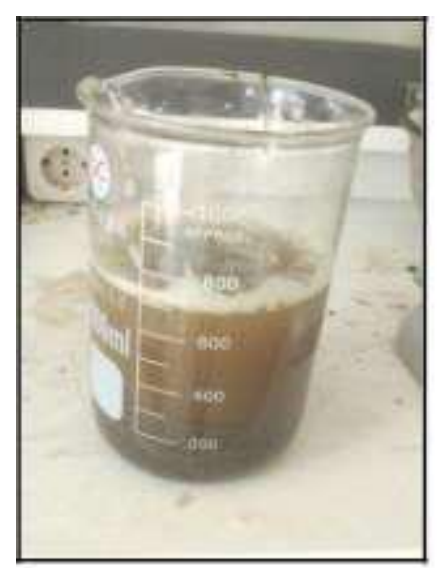

Gambar 1. Setelah diaduk

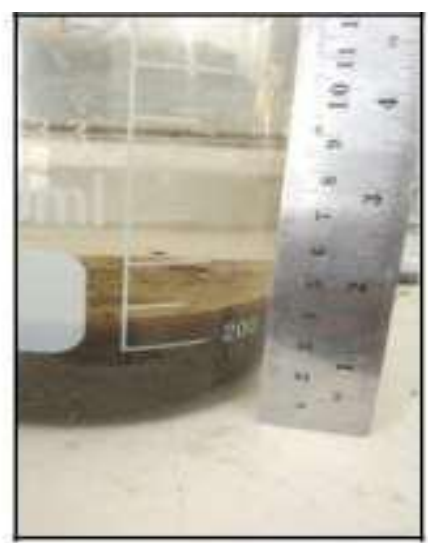

Gambar 2. Setelah diaduk dan didiamkan 24 jam

Berdasarkan gambar diatas diketahui yaitu :

Kadar Lumpur $(\%)=\frac{(\mathrm{A}-\mathrm{B})}{\mathrm{B}} \quad \mathrm{x} 100 \%$

Kadar Lumpur $(\%)=\frac{(4,5-4,4)}{4,5} \times 100 \%=2,22 \%$

Dimana :

A : Tinggi pasir ditambah lumpur

B : Tinggi pasir 
Dari perhitungan diatas, maka telah didapat nilai kadar lumpur yaitu 2,22\% lebih kecil dari standard SK SNI S-04-1998-F,1989, yaitu dibawah 5\%, artinya pasir yang diuji tersebut layak untuk langsung menjadi campuran adonan beton.

\subsection{Hasil Perhitungan Rencana Campuran (Job Mix Formula)}

Dalam penelitian ini, perhitungan komposisi campuran yang digunakan dalam pembuatan benda uji mengacu pada SNI 7394 : 2008, [17] tentang adukan beton setiap $1 \mathrm{~m}^{3}$. Mutu beton yang ditargetkan adalah $\mathrm{Fc}^{\prime}$ 19.6 Mpa atau setara dengan K-200.

Prosentase penambahan air tetes tebu yang dipakai adalah sebesar 10\%, 20\% dan 30\% dengan jumlah masing-masing variabelnya sebanyak 3 buah benda uji pada benda uji kubus . Komposisi material dan bahan disajikan dalam bentuk tabel seperti di bawah ini.

Tabel 1. Komposisi Material Untuk Kebutuhan 1 buah kubus 15/15/15

\begin{tabular}{|c|c|c|c|c|c|}
\hline \multirow{3}{*}{ Bahan } & Jenis Beton & Beton & $\begin{array}{c}\text { Beton } \\
10 \%\end{array}$ & $\begin{array}{c}\text { Beton } \\
20 \%\end{array}$ & $\begin{array}{c}\text { Beton } \\
30 \%\end{array}$ \\
\cline { 2 - 6 } & Satuan & Normal & $\begin{array}{c}\text { Tetes } \\
\text { Tebu }\end{array}$ & $\begin{array}{c}\text { Tetes } \\
\text { Tebu }\end{array}$ & $\begin{array}{c}\text { Tetes } \\
\text { Tebu }\end{array}$ \\
\cline { 2 - 6 } & & $\mathrm{N}$ & TT 10 & TT 20 & TT 30 \\
\hline Semen & $\mathrm{kg}$ & \multicolumn{4}{|c|}{1,19} \\
\hline Pasir & $\mathrm{kg}$ & \multicolumn{4}{|c|}{2,47} \\
\hline Koral & $\mathrm{kg}$ & \multicolumn{4}{|c|}{3,48} \\
\hline Air & liter & \multicolumn{4}{|c|}{0,73} \\
\hline $\begin{array}{c}\text { Tetes } \\
\text { Tebu }\end{array}$ & liter & - & 0,073 & 0,145 & 0,23 \\
\hline
\end{tabular}

Sumber : Analisa Perhitungan Data

Tabel 2. Komposisi Material Untuk Kebutuhan 1 buah balok

\begin{tabular}{|c|c|c|c|c|c|}
\hline \multirow{3}{*}{ Bahan } & Jenis Beton & Beton & $\begin{array}{c}\text { Beton } \\
10 \%\end{array}$ & $\begin{array}{c}\text { Beton } \\
20 \%\end{array}$ & $\begin{array}{c}\text { Beton } \\
30 \%\end{array}$ \\
\cline { 2 - 6 } & Satuan & Normal & $\begin{array}{c}\text { Tetes } \\
\text { Tebu }\end{array}$ & $\begin{array}{c}\text { Tetes } \\
\text { Tebu }\end{array}$ & $\begin{array}{c}\text { Tetes } \\
\text { Tebu }\end{array}$ \\
\cline { 2 - 6 } & & $\mathrm{N}$ & TT 10 & TT 20 & TT 30 \\
\hline Semen & $\mathrm{kg}$ & \multicolumn{4}{|c|}{2,38} \\
\hline Pasir & $\mathrm{kg}$ & \multicolumn{4}{|c|}{4,94} \\
\hline Koral & $\mathrm{kg}$ & \multicolumn{4}{|c|}{6,96} \\
\hline Air & liter & \multicolumn{4}{|c|}{1,45} \\
\hline $\begin{array}{c}\text { Tetes } \\
\text { Tebu }\end{array}$ & liter & - & 0,145 & 0,290 & 0,435 \\
\hline
\end{tabular}

Sumber : Analisa Perhitungan Data 


\subsection{Berat Volume}

Pengujian berat volume pada benda uji ini dilakukan saat usia sample tersebut mencapai 28 hari, [18]. Adapun hasil pengujiannya terlihat pada tabel berikut.

Tabel 4. Berat Volume Satuan Beton Kubus Penambahan tetes tebu

\begin{tabular}{|c|c|c|c|}
\hline No & $\begin{array}{c}\text { Tetes } \\
\text { tebu }\end{array}$ & $\begin{array}{c}\text { Berat rata- } \\
\text { rata }(\mathrm{Kg})\end{array}$ & $\begin{array}{c}\text { Volume } \\
(\mathrm{Kg} / \mathrm{m} 3)\end{array}$ \\
\hline 1 & $0 \%$ & 7,86 & 26527,5 \\
2 & $10 \%$ & 7,51 & 25329,38 \\
3 & $20 \%$ & 7,57 & 25531,88 \\
4 & $30 \%$ & 7,75 & 26156,25 \\
\hline
\end{tabular}

Sumber : Analisa Perhitungan Data

Dari tabel di atas dapat dilihat bahwa penurunan berat volume pada benda uji dengan prosentase penambahan air tetes tebu menjadi yang paling rendah dari beton normal.

Dapat dilihat dari gambar grafik berikut ini.

Grafik 1. Berat Volume

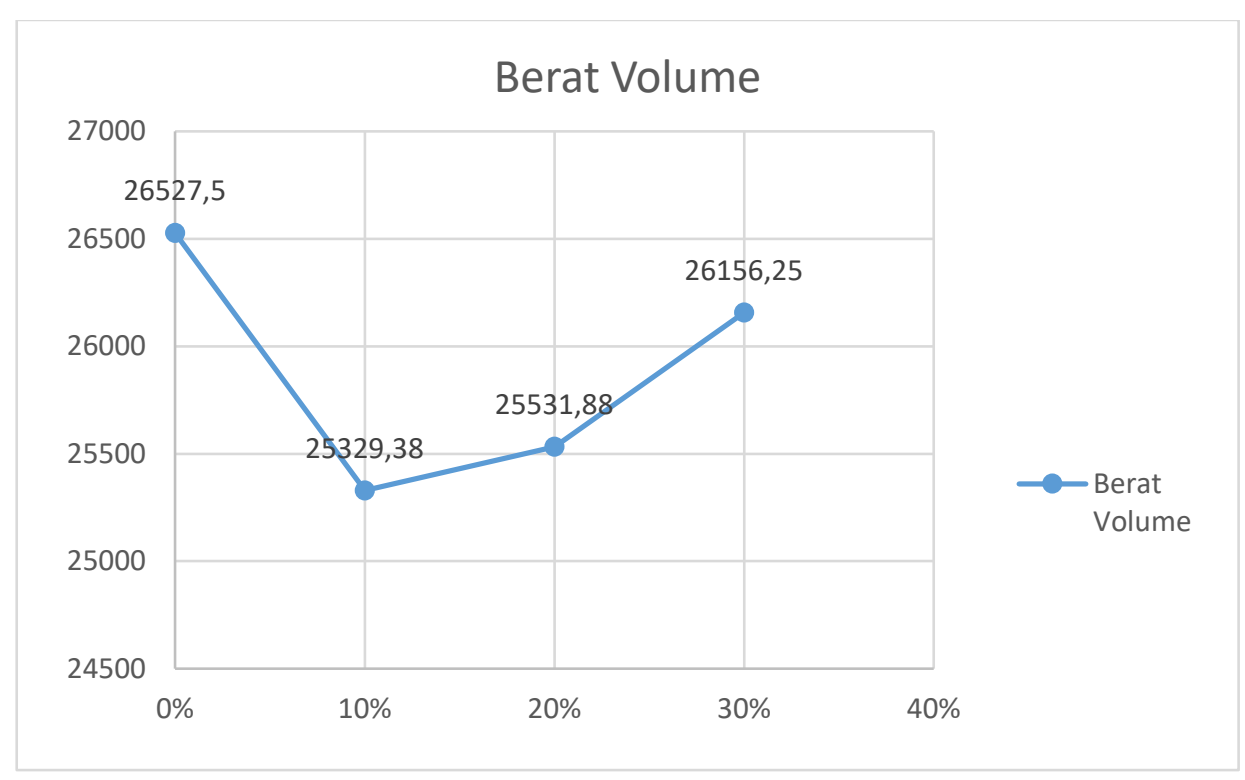

Sumber : Analisa Perhitungan Data 
Tabel 5. Berat Volume Satuan Beton Balok Penambahan tetes tebu

\begin{tabular}{|c|c|c|c|}
\hline No & Tetes tebu & Berat rata-rata $(\mathrm{Kg})$ & Berat Volume $(\mathrm{Kg} / \mathrm{m} 3)$ \\
\hline 1 & $0 \%$ & 33,45 & 2333137,5 \\
2 & $10 \%$ & 33,65 & 2347087,5 \\
3 & $20 \%$ & 33,60 & 2343600 \\
4 & $30 \%$ & 33,55 & 2340112,5 \\
\hline
\end{tabular}

Sumber : Analisa Perhitungan Data

Begitu pula dengan sampel benda uji balok mengalami kenaikan berat volume tertinggi yaitu pada penamban tetes tebu. Sehingga dari data diatas dapat di tarik garfik sebagai berikut :

Grafik 2. Berat Satuan Beton

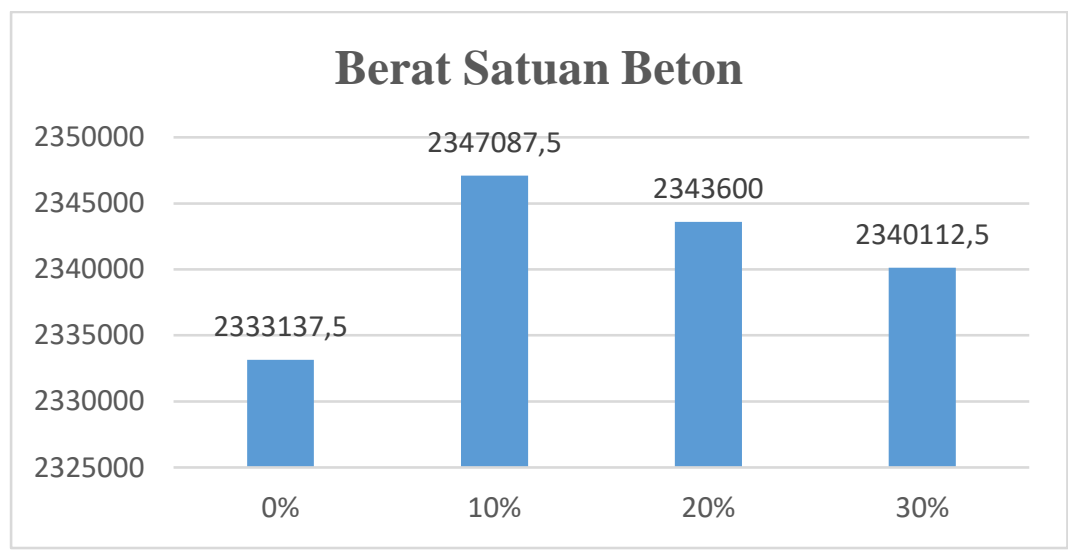

Sumber : Analisa Perhitungan Data

\subsection{Hasil Pengujian Kuat Tekan}

Pengujian kuat tekan menggunakan alat CTM dengan kuat tekan mencapai 500 ton. Benda uji yang dipakai dengan dimensi 15 x $30 \mathrm{~cm}$ dengan umur 28 hari. Tes kuat tekan ini berdasarkan SNI 03-1974-1996, [19].

Setelah dilakukan pengujian semua benda uji, untuk menghitung kuat tekan beton dengan rumus dibawah ini.

$F^{\prime} \mathrm{cf}=\frac{\mathrm{P}}{\mathrm{A}}$

Dimana :

F'cf = Kuat tekan beton/beton serat $(\mathrm{Mpa})$

$\mathrm{P} \quad=$ Beban tekan maksimum $(\mathrm{N}) \quad=1000 \mathrm{Kg}$

A $\quad=$ Luas penampang silinder $=114 \pi \mathrm{D}^{2}\left(\mathrm{~mm}^{2}\right)$

F'cf $=\underline{298,50}=\underline{298,500}=16,90 \mathrm{Mpa}$ 
Setelah melakukan perhitungan kuat tekan beton 28 hari, perhitungan disajikan dalam tabel berikut.

Tabel 6. Kuat Tekan Beton 28 Hari

\begin{tabular}{|c|c|c|c|c|c|}
\hline \multirow{4}{*}{ No. } & \multirow{4}{*}{$\begin{array}{c}\text { Air Tetes } \\
\text { Tebu }\end{array}$} & \multirow{4}{*}{$\begin{array}{c}\text { Berat } \\
\begin{array}{c}\text { Sampel } \\
\text { (kg) }\end{array}\end{array}$} & Beban P & $\begin{array}{c}\text { Kuat } \\
\text { Tekan }\end{array}$ & $\begin{array}{l}\text { Kuat } \\
\text { Tekan }\end{array}$ \\
\hline & & & \multirow{3}{*}{$(\mathbf{k N})$} & \multirow{3}{*}{$\begin{array}{r}28 \text { Hari } \\
\text { (MPa) }\end{array}$} & \multirow{3}{*}{$\begin{array}{c}\text { Rata - } \\
\text { Rata } \\
\text { MPa }\end{array}$} \\
\hline & & & & & \\
\hline & & & & & \\
\hline 1 & & 7,86 & 298,5 & 16,9 & \\
\hline 2 & $0 \%$ & 7,8 & 298,1 & 16,88 & 16,9 \\
\hline 3 & & 7,85 & 299 & 16,93 & \\
\hline 1 & & 7,48 & 299 & 16,93 & \\
\hline 2 & $10 \%$ & 7,51 & 295,12 & 16,71 & 16,73 \\
\hline 3 & & 7,48 & 292,33 & 16,55 & \\
\hline 1 & & 7,55 & 294,25 & 16,66 & \\
\hline 2 & $20 \%$ & 7,57 & 295,68 & 16,74 & 16,67 \\
\hline 3 & & 7,5 & 293,5 & 16,62 & \\
\hline 1 & & 7,49 & 289,95 & 16,42 & \\
\hline 2 & $30 \%$ & 7,55 & 287,3 & 16,27 & 16,27 \\
\hline 3 & & 7,75 & 284,89 & 16,13 & \\
\hline
\end{tabular}

Sumber : Analisa Perhitungan Data

Dengan hasil dari tabel diatas ternyata untuk campuran beton dengan adanya penambahan tetes tebu mengalami perbedaan kuat tekan beton terhadap campuran beton normal.

Hasil kuat tekan pada tabel rekapitulasi di atas disajikan dalam bentuk gambar grafik pada masing-masing hasil kuat tekan berdasarkan kadar tetes tebu seperti grafik pada gambar dibawah ini.

Grafik 3. Hasil kuat tekan sampel $1(0 \%)$

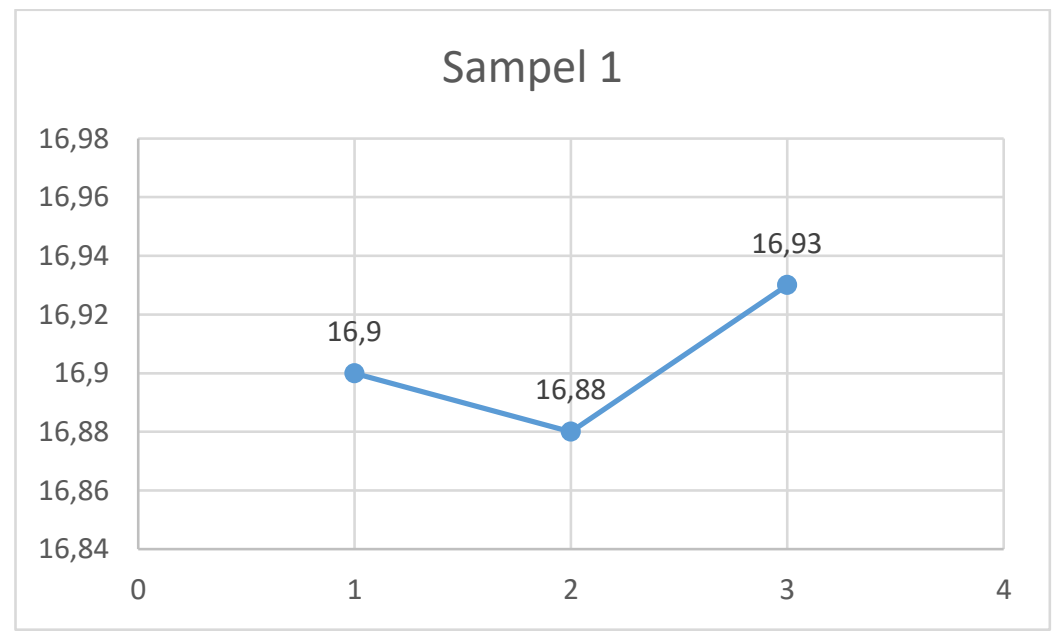

Sumber : Analisa Perhitungan Data 
Grafik 4. Hasil kuat tekan sampel 2 (10\%)

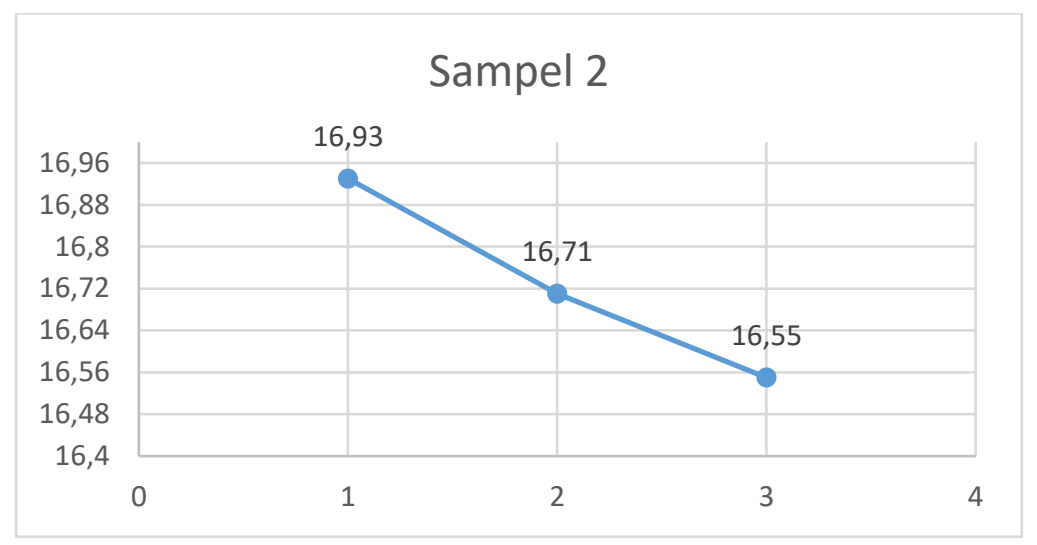

Sumber : Analisa Perhitungan Data

Grafik 5. Hasil kuat tekan sampel 3 (20\%)

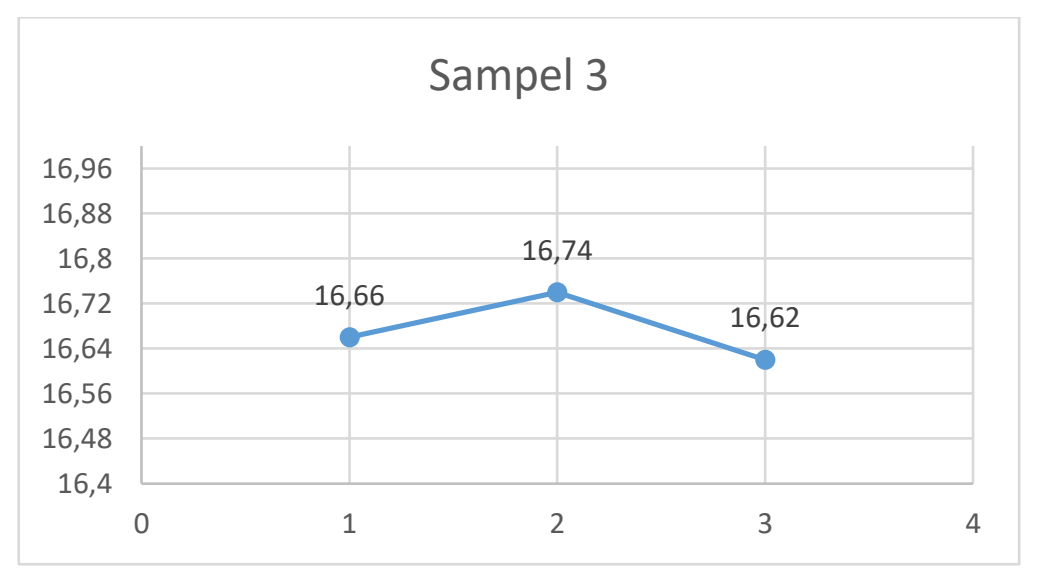

Sumber : Analisa Perhitungan Data

Grafik 5. Hasil kuat tekan sampel 4 (30\%)

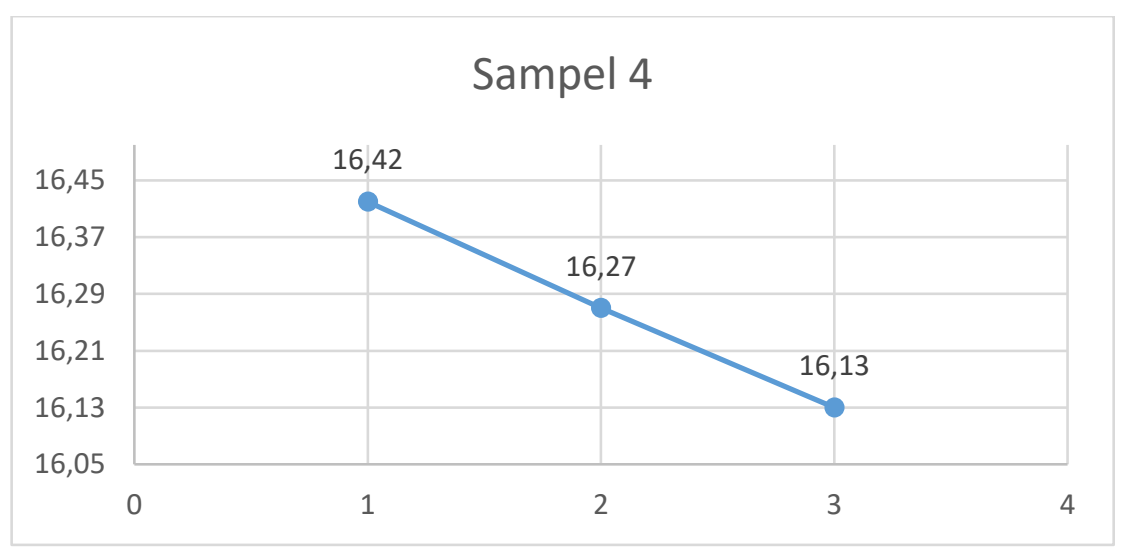

Sumber : Analisa Perhitungan Data

Berdasarkan hasil masing-masing sampel diatas, dapat diketahui perbandingan kekuatan beton menurut kadar tetes tebu yang digunakan dan disajikan dalam gambar dibawah ini : 
Grafik 6. Hasil kuat tekan

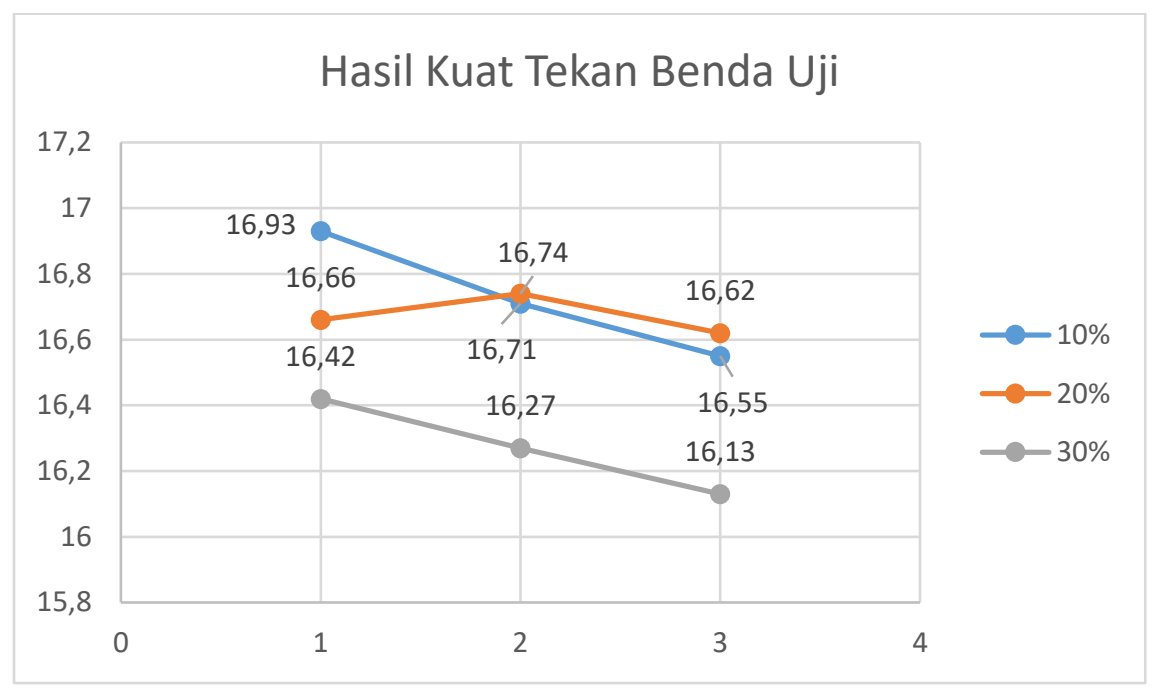

Sumber : Analisa Perhitungan Data

Berdasakan data diatas, kita bisa mengetahui perbandingan kuat tekan beton sesuai dengan kandungan tetes tebu. Kuat tekan yang tertinggi yaitu pada sampel 1 benda uji no 1 kandungan air tetes tebu $10 \%$.

Grafik 7. Penambahan Tetes Tebu Optimum

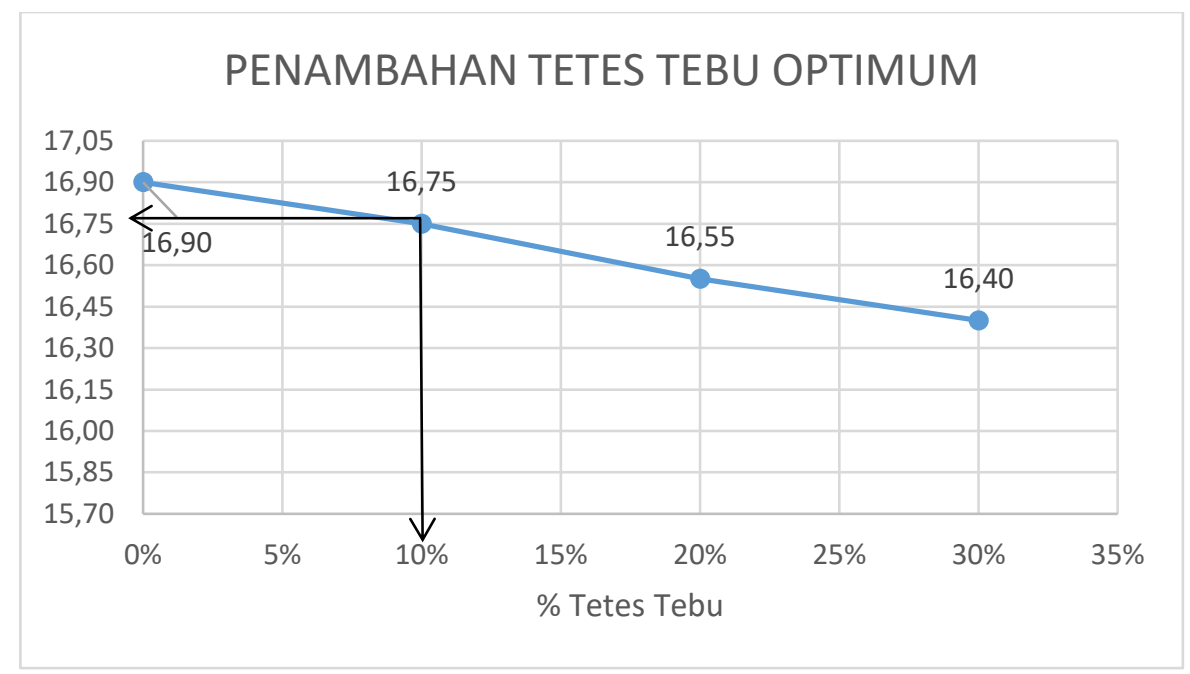

Sumber : Analisa Perhitungan Data

Dari hasil kuat tekan yang diperoleh dari pengujian semua benda uji, kemudian dapat diketahui penambahan air tetes tebu yang paling optimum dengan cara menarik garis tegak lurus terhadap kuat tekan yang direncanakan yaitu sebesar 16,75 MPa. 
Berdasarkan grafik diatas, untuk penambahan tetes tebu yang paling rendah yaitu $30 \%$ dapat mencapai kuat tekan sebesar 16,40 MPa. Semakin banyak penambahan tetes tebu pada adonan beton semakin rendah pula nilai kuat tekan beton yang dihasilakan berdasarkan grafik diatas.

\subsection{Hasil Pengujian Kuat Lentur}

Pengujian kuat lentur menggunakan alat hydraulic Jack dengan kapasitas mencapai 32 ton. Benda uji yang dipakai berbentuk balok dengan dimensi 15 x 15 x $60 \mathrm{~cm}$ dengan umur 28 hari, [20].

Setelah dilakukan pengujian kuat lentur pada semua benda uji, maka hasil yang didapatkan terlihat pada tabel 7 dengan rumus sebagai berikut.

$$
\begin{aligned}
& \sigma=\frac{\mathrm{P} \times \mathrm{L}}{\mathrm{b \times h} \mathrm{h}_{2}} \\
& \sigma=\frac{40 \times 450}{155 \times 155^{2}}=\frac{40000 \times 450}{155 \times 24025}=\frac{18000000}{3723875}=4,83 \mathrm{Mpa}
\end{aligned}
$$

Tabel 7. Pengujian Kuat Lentur

\begin{tabular}{|c|c|c|c|c|c|c|c|}
\hline \multirow{2}{*}{ No } & \multirow{2}{*}{\begin{tabular}{c} 
Jenis \\
\multirow{2}{*}{ Bahan }
\end{tabular}} & Berat & \multicolumn{3}{|c|}{ Ukuran Rata- rata } & \multirow{2}{*}{ Beban } & $\begin{array}{c}\text { Kuat } \\
\text { Lentur }\end{array}$ \\
\cline { 3 - 6 } \cline { 3 - 6 } & & $(\mathrm{Kg})$ & Lebar & Tinggi & Panjang & & 28 Hari \\
\cline { 3 - 6 } & & & $(\mathrm{cm})$ & $(\mathrm{cm})$ & $(\mathrm{cm})$ & $(\mathrm{Mpa})$ & $(\mathrm{Mpa})$ \\
\hline 1 & Normal & 33,45 & 155 & 155 & 6 & 40 & 4,83 \\
\hline 2 & $10 \%$ & 33,65 & 155 & 155 & 6 & 41 & 4,94 \\
\hline 3 & $20 \%$ & 33,6 & 155 & 155 & 6 & 41 & 4,96 \\
\hline 4 & $30 \%$ & 33,55 & 155 & 155 & 6 & 42 & 5 \\
\hline
\end{tabular}

Sumber : Analisa Perhitungan Data

Hasil kuat lentur beton pada tabel rekapitulasi di atas disajikan dalam bentuk grafik pada gambar berikut :

Grafik 8. Hasil Pengujian Kuat Lentur

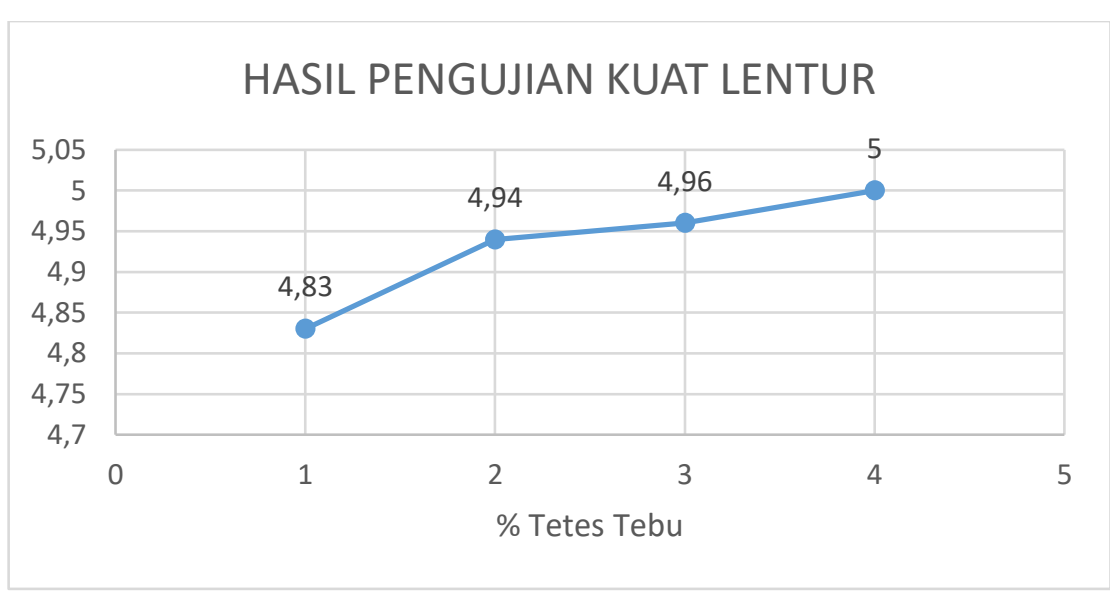

Sumber : Analisa Perhitungan Data 
Setelah selesai melakukan uji kuat lentur beton, dapat dihasilkan bahwa beton yang mengandung campuran tetes tebu nilai kuat lenturnya lebih besar dari pada sampel beton normal. Dengan campuran paling tinggi 30\% yaitu: 5,00Mpa. Dengan demikian semakin banyak campuran tetes tebu maka kuat lentur beton semakin tinggi.

\section{KESIMPULAN}

Hasil dari pengetesan uji kuat tekan beton dan kuat lentur beton dengan menggunkaan air limbah Tetes Tebu sebagai berikut:

Setelah selesai melakukan uji kuat lentur beton, dapat dihasilkan bahwa beton yang mengandung campuran tetes tebu nilai kuat lenturnya lebih besar dari pada sampel beton normal. Dengan campuran paling tinggi 30\% yaitu: 5,00Mpa. Dengan demikian semakin banyak campuran tetes tebu maka kuat lentur beton semakin tinggi.

\section{SARAN}

Sebaiknya di adakan pengkajian lebih dalam tentang penggunaan air limbah tetes tebu sebagai ganti air serta penambahan bahan-bahan limbah lainnya sehingga didapatkan beton yang ramah bagi lingkungan dengan kwualitas yang bagus.

\section{UCAPAN TERIMAKASIH}

Dalam penyusunan artikel ini, penulis ucapkan terimakasih kepada dosen pembimbing dan Universitas Kadiri. Penulis berharap agar artikel ini dapat bermanfaat bagi pembaca.

\section{DAFTAR PUSTAKA}

[1] A. I. Candra and E. Siswanto, "Rekayasa Job Mix Beton Ringan Menggunakan Hydroton Dan Master Ease 5010,” J. CIVILA, vol. 3, no. 2, p. 162, 2018, doi: 10.30736/cvl.v3i2.258.

[2] A. I. Candra, E. Gardjito, Y. Cahyo, and G. A. Prasetyo, "Pemanfaatan Limbah Puntung Rokok Filter Sebagai Bahan Campuran Beton Ringan Berpori,” UKaRsT, vol. 3, no. 1, p. 82, 2019, doi: 10.30737/ukarst.v3i1.365.

[3] R. Hepiyanto and M. A. Firdaus, "Pengaruh Penambahan Abu Bonggol Jagung Terhadap Kuat Tekan Beton K - 200,” UKaRsT, vol. 3, no. 2, p. 1, 2019, doi: 10.30737/ukarst.v3i2.475.

[4] B. B. Leovie Haf, "Pengaruh Penggunaan Fly Ash Pada Beton Mutu Normal Dan Mutu Tinggi Ditinjau Dari Kuat Tekan Dan Absorbsi,” J. Media Tek. Sipil, vol. 10, no. 1, pp. 2-5, 2013, doi: 10.22219/jmts.v10i1.1206.

[5] A. Syafi' urroziq, Y. C. SP, and L. D. Krisnawati, "PEMANFAATAN SERBUK KACA 
DARI JENIS KACA BENING DENGAN KETEBALAN 3-4 MM SEBAGAI BAHAN TAMBAH DALAM PEMBUATAN BATAKO,”Jurmateks, vol. 1, no. 1, pp. 44-55, 2018.

[6] F. Akbar, A. Ariyanto, M. Eng, ) Bambang Edison, and S. Pd, "Penggunaan Tempurung Kelapa Terhadap Kuat Tekan Beton K-100,” J. Mhs. Tek. 2014 - e-journal.upp.ac.id, vol. 1, no. 1, pp. 1-11, 2014.

[7] A. Y. Bintoro, A. D. Limantara, and S. Winarto, "EVALUASI KEKUATAN CONCBLOCK DENGAN AGREGAT HALUS DAN AGREGAT KASAR DARI TEMPURUNG KELAPA,” Jurmateks, vol. 1, no. 1, pp. 160-171, 2018.

[8] M. Mulyati and A. Adman, "Pengaruh Penambahan Cangkang Kemiri dan Sikacim Concrete Additive terhadap Kuat Tekan Beton Normal," J. Tek. Sipil ITP, vol. 6, no. 2, pp. 38-45, 2019, doi: 10.21063/jts.2019.v602.01.

[9] H. Hardjasaputra, V. Indrawati, and I. Djohari, "Pengaruh penggunaan serat polypropylene dan micro steel fiber pada ketahanan api dari ultra high perfomance concrete (UHPC) untuk bangunan infrastruktur (021M)," KoNTekS 7 UNS, vol. 7, no. KoNTekS 7, pp. 24-26, 2013.

[10] H. Prayuda and A. Pujianto, "Analisis Kuat Tekan Beton Mutu Tinggi Dengan Bahan Tambah Superplastisizer dan Limbah Las Karbit,” Rekayasa Sipil, vol. 12, no. 1, pp. 32 38, 2018, doi: 10.21776/ub.rekayasasipil/2018.012.01.5.

[11] T. Wonlele, S. M. Dewi, and S. Nurlina, "Penerapan bambu sebagai tulangan dalam struktur rangka batang beton bertulang," Rekayasa Sipil, vol. 7, no. 1, pp. 1-12, 2013.

[12] A. Susanto, Y. C. S. P, and S. Winarto, "STUDI PERENCANAAN JEMBATAN CUMPLENG DENGAN METODE PRATEKAN DI KEC. SLAHUNG KABUPATEN PONOROGO,” Jurmateks, vol. 1, no. 2, pp. 172-181, 2018.

[13] T. P. G. A, Y. C. S. P, S. Winarto, and A. I. Candra, "PERBANDINGAN KEKUATAN BETON DENGAN CAMPURAN DRAMIX STEEL FIBER DAN TULANGAN WIREMESH PADA RIGID PAVEMENT,”Jurmateks, vol. 1, no. 2, pp. 313-324, 2018.

[14] Badan Standardisasi Nasional Indonesia, "SNI 2847 : 2013 Persyaratan Beton Struktural untuk Bangunan Gedung,”pp. 1-265, 2013.

[15] E. Gardjito, A. I. Candra, and Y. Cahyo, "Pengaruh Penambahan Batu Karang Sebagai Substitusi Agregat Halus Dalampembuatan Paving Block," UKaRsT, vol. 2, no. 1, p. 35, 2018, doi: 10.30737/ukarst.v2i1.374.

[16] R. Manuahe et al., "Kuat Tekan Beton Geopolymer Berbahan Dasar Abu Terbang," J. Sipil Statik, vol. 2, no. 1, pp. 277-282, 2014, doi: 10.5614/jts.2013.20.1.1.

[17] SNI 2417-2008, "Standar Nasional Indonesia Cara uji keausan agregat dengan mesin 
abrasi Los Angeles," 2008.

[18] A. C. Sembiring and J. J. Saruksuk, "Uji Kuat Tekan Dan Serapan Air Pada Paving Block dengan Bahan Pasir Kasar, Batu Kacang, dn Pasir Halus," JURITI PRIMA (Junal Ilm. Tek. Ind. Prima), vol. 1, no. May, 2018, doi: 10.5281/zenodo.1207331.

[19] SNI 03-1974-1990, "Metode pengujian kuat tekan beton," 1990.

[20] SNI 4431:2011, "Cara uji kuat lentur beton normal dengan dua titik pembebanan," Standar Nas. Indones., p. 16, 2011. 